\title{
Fetal valproate syndrome: is there a recognisable phenotype?
}

\author{
R M WINTER*, D DONNAI†, J BURN ${ }^{*}$, AND S M TUCKER \$ \\ From * The Kennedy Galton Centre for Clinical Genetics, Radlett, Hertfordshire, WD79HQ, and Division of \\ Inherited Metabolic Disease, Clinical Research Centre, Northwick Park Hospital, Harrow HA1 3 UJ; \\ $\dagger$ Department of Medical Genetics, St Mary’s Hospital, Manchester M13 0JH; $¥$ Regional Genetics Advisory \\ Service, University of Newcastle Upon Tyne, Newcastle Upon Tyne NE2 4AA; and \$Paediatric Department, \\ Hillingdon Hospital, Hillingdon, Middlesex UB8 3NN.
}

SUMMARY Four infants who were exposed to sodium valproate or valproic acid during: pregnancy are described. Common facial features in the three surviving infants include epicanthic $-\vec{\sigma}$ folds, a flat nasal bridge, a broad nasal base, anteverted nostrils, a shallow philtrum, and a thin upper lip with a thick lower lip. Ridging of the metopic suture, congenital heart defect, postaxialo polydactyly, and hypospadias were additional features in individual cases. In agreement with previous authors, we feel that there is a distinctive 'fetal valproate' phenotype.

There have been several reports of congenital malformations occurring in the offspring of mothers who have taken sodium valproate or valproic acid during pregnancy as a treatment for epilepsy. ${ }^{1-6}$ In addition, it has been suggested that valproic acid ingestion is associated with neural tube defects. ${ }^{7-9}$

Recently DiLiberti et al $^{10}$ reported seven infants who had been exposed to sodium valproate in utero and claimed to be able to recognise a consistent facial phenotype, and a further case was reported by Tein and MacGregor. ${ }^{11}$ We report four further infants, exposed to sodium valproate during pregnancy, whose features consolidate and expand the spectrum of anomalies previously reported.

\section{Case reports}

CASE 1

The parents of this baby were Caucasian and unrelated. The mother took valproic acid, $400 \mathrm{mg}$ four times a day, throughout pregnancy for grand mal epilepsy. The baby, a boy, was born at term by normal delivery weighing $3.9 \mathrm{~kg}$, head circumference $35 \mathrm{~cm}$. There was a grand mal seizure in the neonatal period. On examination (figs 1 and 2) he was noted to have a tall, hirsute forehead with depressed nasal bridge, hypertelorism, epicanthic folds, a long, shallow philtrum, small mouth with thin upper and full lower lip, and bilateral low set

Received for publication 25 Junc 1986.

Revised version accepted for publication 1.3 October 1986. and posteriorly rotated ears with prominent lobes $\stackrel{\mathbb{D}}{.}$ The chest was shield-like with pectus excavatum $\overrightarrow{0}$ There was polydactyly of the right fifth finger åxp clinodactyly of the left fifth finger with mild talige:

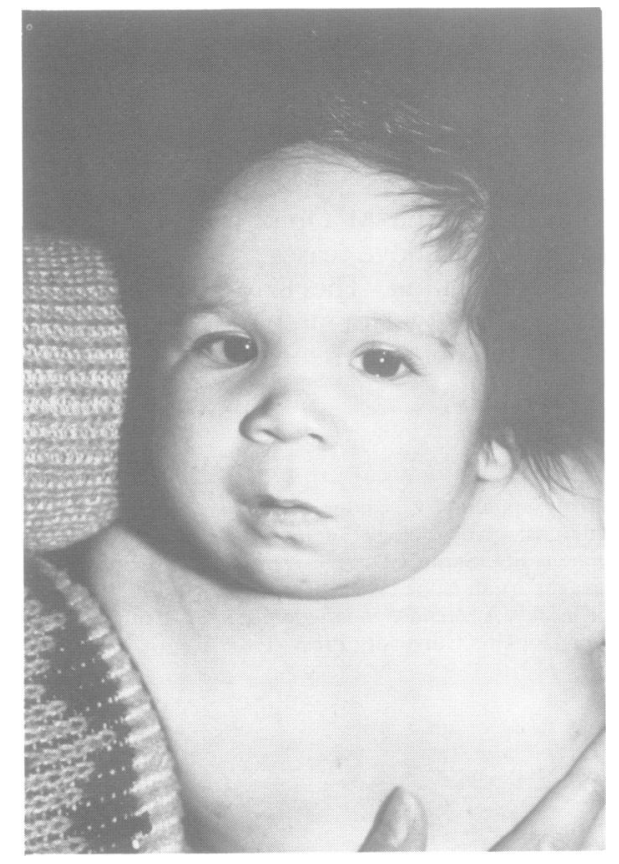

FIG 1 Case 1 aged two months. 


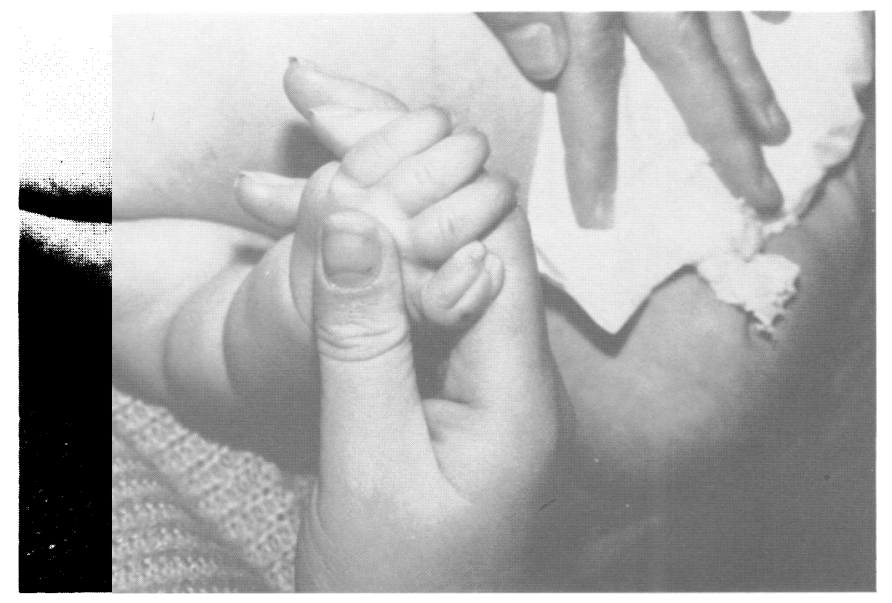

FIG 2 Hands of case 1 at two months.

equinovarus of the feet. First degree hypospadias was present. Chromosome analysis showed a normal $46, X Y$ karyotype.

\section{CASES 2 AND 3}

These children were born to a 22 year old mother and 23 year old father. The mother had suffered from grand mal epilepsy from the age of 16 years. In the first pregnancy she had received sodium valproate, $800 \mathrm{mg}$ three times a day, throughout. Ultrasound scan revealed an abdominal wall defect and spontaneous labour occurred at 32 weeks' gestation. The baby, case 2, a male, had a large ruptured exomphalos containing liver and small bowel. Following repair the baby died. At necropsy it was noted that the body weight was below 1 SD for the gestational age, there was a short frenulum, a high ventricular septal defect, and the second and fourth toes of both feet overrode the third toes.

In the second pregnancy the mother received 800 mg sodium valproate three times a day and there were no major complications. The baby, case 3 , a male, was born at term after a normal delivery, and weighed $3.2 \mathrm{~kg}$. Initially there was some respiratory distress secondary to a chest infection which responded to antibiotic therapy. On the third day the baby developed a heart murmur with evidence of right ventricular hypertrophy on chest radiograph and ECG. An echocardiogram revealed pulmonary stenosis. When evaluated in the genetic clinic at the age of three months (fig 3) his weight was $4.6 \mathrm{~kg}$ and OFC $38.4 \mathrm{~cm}$. There was marked ridging of the metopic suture and trigonocephaly. He had a depressed nasal bridge, thin upper lip, and prominent lower lip. Both ears were low set and posteriorly rotated. There was excess lax skin in the nuchal region. He had a grade 3 hypospadias but both testes were descended. The fifth toes of both feet were proximally placed and overlapped the fourth toes (fig 4). His head control was poor, he had not smiled, and it was difficult to make him fix visually. Chromosome analysis showed a normal 46,XY karyotype. At the age of five months he had developed clinical and radiological evidence of craniosynostosis of the metopic and left lambdoid suture.

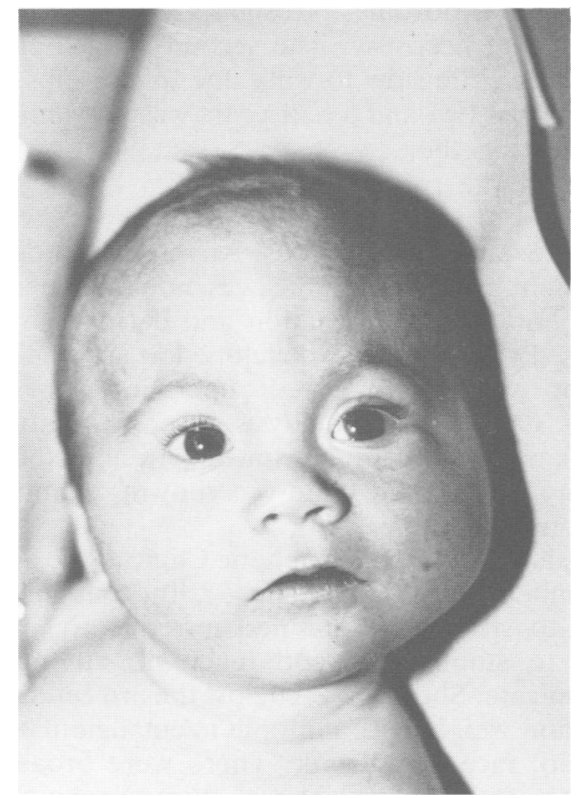

FIG 3 Case 3 aged three months. 


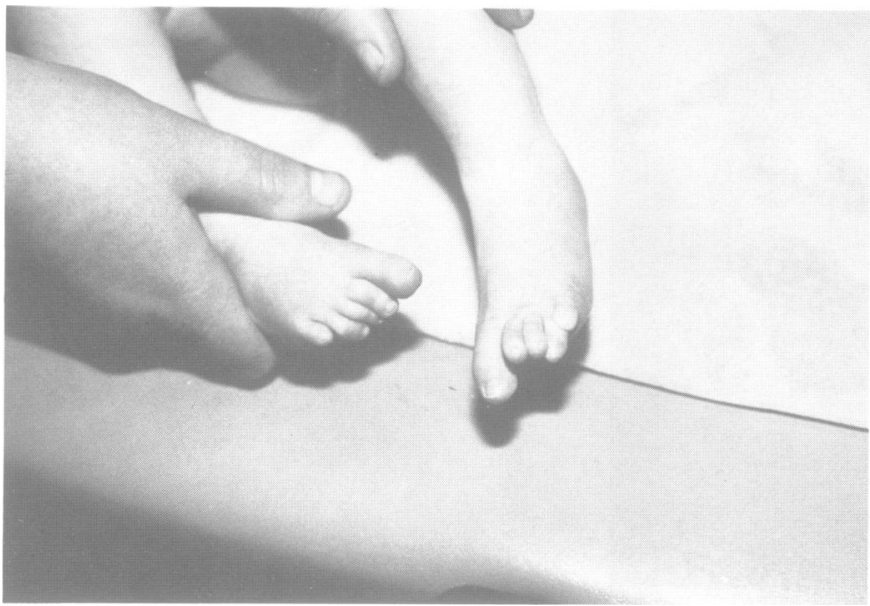

FIG 4 Feet of case 3 at three months.

\section{CASE 4}

This baby, a female, was born to unrelated parents of European origin. Her mother had suffered from epilepsy from the age of 16 years. Control was poor on phenytoin, which had been discontinued two years before and was followed by the introduction of sodium valproate $500 \mathrm{mg}$ and carbamazepine $200 \mathrm{mg}$ three times a day. The couple had two previous children, both born before the change in medication. The first child, born in 1981, had died at the age of five months and was diagnosed as a case of sudden infant death syndrome. No significant abnormality was found at necropsy. The second child, born in 1982 , was a little slow to walk due to stiff hips, but by the age of two and a half years was beginning to put words together.

At birth the proband weighed $3.3 \mathrm{~kg}$ and was noted to be of somewhat unusual appearance with a cleft palate and broad big toes. An inital diagnosis of Rubenstein-Taybi syndrome was not sustained by subsequent $x$ ray examination and dermatoglyphic analysis. Pyloric stenosis developed at six weeks of age, for which a Ramstedt operation was performed. Chromosome analysis revealed a normal $46, \mathrm{XX}$ karyotype, but it became apparent by the age of six months that the child was showing significant developmental delay.

On examination in the Genetic Clinic at the age of eight and a half months (fig 5), the patient was unable to sit unaided, smiled infrequently in response to stimulation, and made no attempt to communicate. She was well below the 3 rd centile for height and weight with multiple haemangiomata on the scalp, face, and trunk. There were broad big toes but normal thumbs. The sternum was short with widely spaced nipples.
Craniofacial abnormalities consisted of microg- $\vec{z}$ nathia, hypertelorism, a divergent squint, anteverted nostrils, and a long, shallow philtrum. The mouth was small, with a thin upper lip and full, everted lower lip. There was a rather brachy-黑 cephalic skull, but no evidence of abnormal suture $\overrightarrow{0}$ fusion, a point confirmed by the hair whorl beigg close to the vertex of the skull. The lower helices $\mathrm{Gf}$ the ears showed incomplete formation, there wasia median groove of the tongue, and a posterior cleft palate. A specific feature referred to in othero children with a so-called fetal valproate syndrome was a rather prominent infraorbital groove.

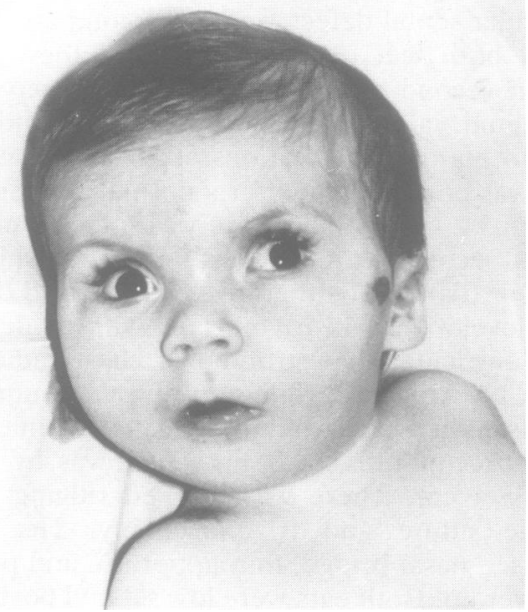

FIG 5 Case 4 aged eight and a half months. 


\section{Discussion}

The main purpose of this paper is to consolidate the suggestion that there is a recognisable 'fetal valproate' syndrome. Such a hypothesis would depend on there being a characteristic facial phenotype, as well as a similar spectrum of congenital anomalies in affected infants.

The facial features in infants exposed to sodium valproate in infancy were first analysed in detail by DiLiberti et al. ${ }^{10}$ They stated that the facial phenotype is characterised by "epicanthal folds connecting with an infraorbital crease or groove, a flat nasal bridge, a small nose with anteverted nostrils, long upper lip with relatively shallow philtrum, a relatively small mouth with downturned angles, and a thin upper vermilion border". The cases presented here show many of these features. We are particularly impressed with the appearance of the nose, philtrum, and lips. Although small, the nose usually has a broad base with a flat nasal bridge and anteverted nares. The philtrum is long and shallow, so that the two pillars are sometimes indistinct, as in case 4 . The combination of a small oral opening, thin upper lip, and relatively full lower lip imparts a characteristic appearance to the mouth, which is carp shaped. These features can also be seen in the case reported by Tein and MacGregor. ${ }^{11}$ The ears have been reported to be variously low set or posteriorly rotated. Two of our cases had rather fleshy, prominent lobes, although incomplete development of the lobes of the ears has also been reported (DiLiberti et al, ${ }^{10}$ case 1). A narrow bifrontal diameter has been noted and in many cases the forehead also appears to be tall. Case 3 had marked ridging of the metopic suture and trigonocephaly, a feature that has been specifically noted before (DiLiberti et al, ${ }^{10}$ case 5) and is apparent from photographs of other cases.

Although low birth weight has been reported previously, none of our cases fell into this category. Malformations seen in our patients which have been reported before include congenital heart defect ${ }^{2} 56^{10}$ and polydactyly reported by Bailey et $a l,{ }^{5}$ who described sibs, one of whom had bilateral finger-like thumbs with a rudimentary digit arising from the base of the right thumb. The other child also had a finger-like thumb without polydactyly. Case 1 of the present report had unilateral postaxial polydactyly. The hypospadias seen in case 1 has also been reported before. ${ }^{511}$ None of the present cases had signs suggestive of a neural tube defect.

Both case 3 and case 4 show signs of significant developmental delay. This certainly seems to be part of the clinical spectrum in some infants exposed to sodium valproate. However, a prospective study is needed to assess the actual risks in any one pregnancy.

In summary, there does appear to be a recognisable spectrum of abnormalities in some infants exposed to sodium valproate. This includes characteristic facial features, low birth weight, and developmental delay in some, and a spectrum of major and minor abnormalities such as congenital heart defect, and defects of the hands, feet, and genitalia.

We would like to thank Dr Susan Huson for helpful comments on the manuscript.

\section{References}

' Dalens B. Raynaud EJ. Gaulme J. Teratogenicity of valproic acid. J Pediatr 1980:97:332-3.

2 Clay SA. McVic R. Chen H. Possible teratogenic effect of valproic acid. J Pediatr 1981:99:828.

${ }^{3}$ Gomez MR. Possible teratogenicity of valproic acid. $J$ Pediatr 1981:98:508-9.

4 Thomas D. Buchanan N. Teratogenic effects of anticonvulsants. J Pediatr 1981:99:163.

5 Bailey CJ. Pool RW. Poskitt EME. Harris F. Valproic acid and fetal abnormality. Br Med J 1983:286:190).

"Koch S, Jager-Roman E. Rating D. Helge H. Possible teratogenic effect of valproate during pregnancy. J Pediatr 1983:103:10)7-8.

7 Robert E. Guibaud P. Maternal valproic acid and congenital neural tube defects. Lancet 1982:ii:937.

* Bjerkedal T. Czeizel A. Goujard J. et al. Valproic acid and spina bifida. Lancet 1982;ii:1096.

${ }^{9}$ Jeavons PM. Sodium valproate and neural tube defects. Lancet 1982;ii:1282-3.

"DiLiberti JH. Ferndon PA. Dennis NR. Curry CJR. The fetal valproate syndrome. Am J Med Genet 1984:19:473-81.

"Tein I. MacGregor DL. Possible valproate teratogenicity. Arch Neurol 1985:42:291-3.

Correspondence and requests for reprints to Dr R M Winter, Kennedy Galton Centre for Clinical Genetics, Harperbury Hospital, Harper Lane, Radlett, Herts WD7 9HQ. 